University of Minnesota Morris Digital Well

University of Minnesota Morris Digital Well

$2-5-2004$

\title{
Limit Orders and the Intraday Behavior of Market Liquidity: Evidence from the Toronto Stock Exchange
}

Minh Vo

Follow this and additional works at: https://digitalcommons.morris.umn.edu/fac_work

Part of the Finance Commons

\section{Recommended Citation}

Vo, Minh, "Limit Orders and the Intraday Behavior of Market Liquidity: Evidence from the Toronto Stock Exchange" (2004). Faculty Working Papers. 2.

https://digitalcommons.morris.umn.edu/fac_work/2

This Article is brought to you for free and open access by the Faculty and Staff Scholarship at University of Minnesota Morris Digital Well. It has been accepted for inclusion in Faculty Working Papers by an authorized administrator of University of Minnesota Morris Digital Well. For more information, please contact skulann@morris.umn.edu. 


\title{
University of MinNesota MoRRIS
}

\section{Working Paper Series}

Limit Orders and the Intraday Behavior of Market Liquidity: Evidence From the Toronto Stock Exchange

\author{
Minh Vo
}

Assistant Professor of Economics

Faculty Center for Learning and Teaching

Rodney A. Briggs Library

Volume 1 Number 5

February 5, 2004

Faculty and Student Research

University of Minnesota, Morris

600 East 4th Street

Morris, MN 56267 
Copyright (C2004 by original author(s). All rights reserved.

\section{Faculty Center for Learning and Teaching}

Engin Sungur, Director

Linda Pederson, Executive Administrative Specialist

\section{Rodney A. Briggs Library}

LeAnn Dean, Director

Peter Bremer, Reference Coordinator

Matt Conner, Instruction Coordinator

Steven Gross, Archivist

Michele Lubbers, Digital Services Coordinator

Shannon Shi, Cataloging Coordinator

\section{Working Paper Series \\ Volume 1, Number 5 \\ 2004}

Faculty Center for Learning and Teaching

Rodney A. Briggs Library

University of Minnesota, Morris

This Working Paper Series allows the broader dissemination of the scholarship of the University of Minnesota-Morris Faculty, staff, and students. It is hoped that this Series will create a broader and much more accessible forum within the borderless academic community, and will further stimulate constructive dialogues among the scholar-teachers at large. 


\title{
Limit Orders and the Intraday Behavior of Market Liquidity: Evidence From the Toronto Stock Exchange
}

\author{
Minh Vo \\ Assistant Professor of Economics
}

University of Minnesota, Morris

Morris, MN 56267, USA

Working Paper Volume 1, Number 5

Copyright@2004 by Minh Vo

All right reserved. 


\section{Table of Contents}

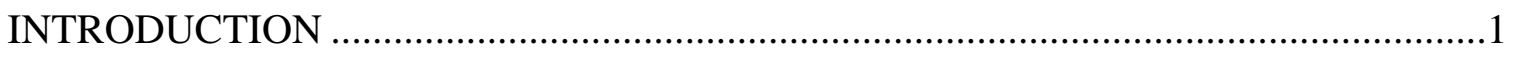

DESCRIPTION OF THE MARKET AND THE DATASET .........................................4

INTRADAY PATTERNS OF LIQUIDITY AND VOLUME OF TSE STOCKS.............5

THE RELATION AMONG LIQUIDITY, VOLUME, AND PRICE VOLATILITY ......14

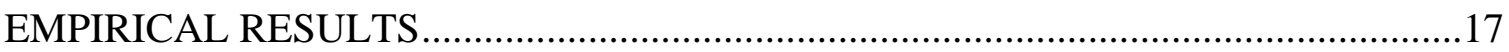

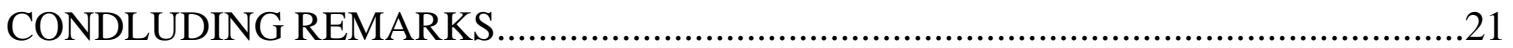




\title{
LIMIT ORDERS AND THE INTRADAY BEHAVIOR OF MARKET LIQUIDITY: EVIDENCE FROM THE TORONTO STOCK EXCHANGE
}

\begin{abstract}
This paper examines the intraday behavior of market liquidity in an order-driven market. Along with previous studies, we show that the U-shaped intraday pattern of spread does not depend on the market architecture. We also find that bid-ask spread and market depth are two dimensions of market liquidity. Market liquidity is inversely related to price volatility. We also investigate the impacts of trading volume on market liquidity. High trading volume implies high liquidity trades and as a result, limit order traders decrease (increase) ask (bid) price and/or increase depth at each quote.
\end{abstract}

\section{INTRODUCTION}

Limit orders play a very important role in providing liquidity to the world stock exchanges of various market architectures. In an order-driven market, such as the Toronto Stock Exchange (TSE), the Paris Bourse, or the Tokyo Stock Exchange, limit orders provide all liquidity to the market. In a specialist market, such as the New York Stock Exchange, a large amount of liquidity comes from limit orders ${ }^{1}$. In a dealership market, such as NASDAQ, some types of limit order trading have been used recently ${ }^{2}$. This paper examines the impacts of price volatility, trading activity, and trading volume on the liquidity in an order-driven market where limit orders play a vital role in liquidity provision.

\footnotetext{
${ }^{1}$ Harris and Hasbrouck (1996) report that limit orders account for 54 percent of all order submitted through SuperDot. Ross, Shapiro and Smith (1996) document that limit orders account for 65 percent of all executed orders and 75 percent of executed shares in SuperDot system.

${ }^{2}$ Market makers in NASDAQ are required to display limit orders.
} 
In a pure order-driven market, investors can submit limit orders or market orders. Limit orders are kept in a limit order book waiting for execution. If a trade takes place, a limit order is executed at a better price than a market order. However, there are risks associated with it. First, a limit order might not be executed. Second, as limit order prices are fixed, there is an adverse selection risk due to the arrival of informed traders. Market orders, on the other hand, are executed with certainty at the bid and ask prices established through previously placed limit orders. However, the execution price may not be favorable.

Glosten (1994) examines an equilibrium model in which there are 2 types of traders. The patient traders place limit orders and therefore supply liquidity to the market. The urgent traders, on the other hand, place market orders and consume liquidity. Informed traders are more likely to be urgent than patient because they want to exploit their super information ${ }^{3}$. Glosten shows that patient traders would not place limit orders unless the expected gains from trading with liquidity traders exceeded the expected loss from trading with informed traders. However, his model does not endogenize the traders' choice between market and limit orders. Handa and Schwartz (1996) extend Glosten's analysis by examining the investors' rational choice between market and limit orders. The choice depends on the investor's beliefs about the probability of his orders being executed against an informed or a liquidity trader. Handa and Schwartz show that in an orderdriven market, if the price is very volatile investors submit more limit orders than market orders because the expected gains from providing liquidity to the market exceed the potential loss from trading with informed traders. Foucault (1999) shows that the price volatility is the main determinant of the mix between market and limit orders. Indeed, if asset price is very volatile, the probability of trading against informed investors and the expected loss to them are larger. Limit order traders have to post higher ask price and lower bid price. This establishes a direct relationship between bid-ask spread and price volatility. Moreover, when price is volatile, market orders become less attractive than limit orders; as a result, more limit orders than market orders are placed.

\footnotetext{
${ }^{3}$ One of the reasons is the value of private information depreciates over time.
} 
According to Harris (1990) liquidity is the willingness of some traders to take the opposite side of a trade that is initiated by someone at low cost. Thus, market liquidity has 2 dimensions: the price dimension, represented by spread, and the quantity dimension, represented by market depth. On the TSE, a complete quote comprises the bid price, the ask price and the depth which is the number of shares available at each price. If liquidity providers believe that there is an increase in the probability of informed trades in the market, they may respond by widening bid-ask spread and/or by quoting less depth at each price. This implies a negative relationship between spread and depth.

On the empirical side, Kavajecz (1999) compares the limit order book spread with the quoted spread of specialists. He finds that specialists play a vital role in narrowing the bid-ask spread, especially for less frequently traded stocks. Chung et al (1999) examine the roles of limit order traders and specialists in NYSE and find that the U-shaped intraday pattern of spreads mostly reflects the intra-day behavior of spreads established by limit order traders. Lee, Mucklow and Ready (1993) show that in the NYSE wide spreads are accompanied by low depths and the liquidity falls in response to high volume and anticipation of earnings announcements.

In this paper, we examine the empirical relation between bid-ask spreads and quoted depths, and the relations among market liquidity, trading activity, price volatility, and trading volume on the TSE, an order-driven market, where all liquidity is provided by limit order traders. We find that there is an inverse relationship between spread and depth. Thus, as in a specialist market, limit order traders in an order driven market use both dimensions of market liquidity to protect themselves from informed traders. We also show that the liquidity is directly related to the volume of trade. Our finding is inconsistent with the prediction of Easley and O'Hara (1992) who show that specialists use trading volume to infer the presence of informed traders. Thus, high volume should be accompanied by wide spread and low depth. However, our finding is consistent with the alternative hypothesis, suggested by Harris and Raviv (1993), that because of the differences of opinion among investors, high volume may mainly reflect high liquidity 
trades and therefore the market is more liquid. In other words, there might be a positive relationship between market liquidity and trading volume.

In addition, we show that market liquidity is inversely related to price volatility. This finding is consistent with the prediction of Handa and Schwartz (1996). We also find that the trading activity which is represented by the number of transactions is negatively related to market liquidity. Harris (1987) shows that the number of trades could have an inverse relationship with price volatility if it reflects the rate of information flow. This can be extended to liquidity. However, Madhavan (1992) suggests that given trading volumes, the number of trades may be positively related to liquidity.

This paper proceeds as follows. Section 2 describes the market and the dataset. Section 3 examines the intraday pattern of depth, spread and volume of TSE stocks. Section 4 presents the empirical relations among spread, depth, volume, price volatility, and trading activity. Section 5 provides some concluding remarks.

\section{DESCRIPTION OF THE MARKET AND THE DATASET}

The TSE has become a pure order-driven market since 1997 when it closed its trading floor. Bid and ask prices are determined by limit buy and sell orders in the absence of specialists. Limit order traders submit their orders to the electronic open book system, which is known as the Computer Assisted Trading System (CATS), through brokers. Limit orders are kept in the system and are executed using strict price and time priority. Trading is conducted on weekdays, Monday to Friday, excluding public holidays. Each trading day commences at 9:30 and ends at 16:00.

Information on the five best bid and ask prices and the corresponding depths is disseminated to the public on the real time basis. Large order traders have the option of not disclosing the part of the order which exceeds 5,000 shares. However, traders might want to make public their orders since the TSE gives priority to disclosed orders over 
undisclosed orders at the same price ${ }^{4}$. For each transaction, the identity of the buyer and the seller is also known to the public. The TSE is as transparent as the Hong Kong Stock Exchange and the Paris Bourse but more transparent than the Tokyo Stock Exchange where only the member of the lead offices can observe orders. This is probably because there is no consensus about the relation between transparency and liquidity.

The dataset is obtained from the Intraday Equity Trades and Quotes Record of the Toronto Stock Exchange. For each transaction, the dataset reports the execution time to the nearest second, the price and the quantity exchanged. For each quote, it reports the posting time, the best bid and ask prices and the quantity demanded or offered at those prices.

In order to have enough observations necessary for intraday time series analysis, we focus on 31 most actively traded component stocks in the TSE 35 Index between September 1, 1999 and November 1, 1999. The list of those stocks is given in the appendix. Although it is the best available database for the current analysis, the dataset still has some limitations. In particular, we do not have order placement other than the best buying or selling limit orders. Therefore, the findings in this chapter need to be interpreted with some caution.

\section{INTRADAY PATTERNS OF LIQUIDITY AND VOLUME OF TSE STOCKS}

\subsection{The Microstructure Models for Intraday Variations in Liquidity}

Several theoretical microstructure models attempt to explain the intraday variation of the bid-ask spread. In the inventory models ${ }^{5}$, the spreads exist in order to compensate the specialists for the risk of holding undesired inventory. Specifically, the specialist adjusts

\footnotetext{
${ }^{4}$ This description of the TSE is drawn from Jiang and Kryzanowski (1998).

${ }^{5}$ See Stoll (1978), Amihud and Mendelson (1980) (1982), Ho and Stoll (1981).
} 
bid and ask prices to go back to the optimal inventory position if the order imbalance moves him out of the desired position.

In the specialist market power models, Brock and Kleidon (1992) show that demand for transactions is less elastic and higher at the opening and closing than at the rest of the day. There are at least two reasons. First, the accumulation of overnight information may change investors' optimal portfolio. Second, at the closing, due to the imminent nontrading period, optimal portfolios can be different from the ones during the continuous trading periods. The specialist, therefore, can charge higher transaction price at those periods. This explains wide spreads at the opening and the closing of the trading day. This result can be extended to a pure order-driven market.

Information models ${ }^{6}$ look at the adverse selection problem faced by the specialist who is at an informational disadvantage relative to informed traders. Therefore, the specialist must keep spreads wide enough so that the profits from trading with liquidity traders sufficiently compensate for the losses from trading with informed traders. In the model of Madhavan (1992), information asymmetry is gradually resolved during the trading day; therefore, spreads decline throughout the day.

While numerous studies have examined the intraday variations in bid-ask spreads during the last two decades or so, only recently have researchers begun to study the behavior and the determinants of quoted depths. Ye (1995) analyzes the optimal strategy of specialists and shows that when the probability of informed trades rises, specialists widen spreads and reduce depth at each quote. He also finds that specialists decrease depths in response to an increase in price volatility. Kavajecz (1999) shows that depths are used by specialists as a strategic variable to reduce risk associated with information events.

\footnotetext{
${ }^{6}$ See Copeland and Galai (1983), Glosten and Milgrom (1985), Kyle (1985), Easley and O'Hara (1987), Madhavan (1992), Foster and Viswanathan (1994).
} 
A market maker in a specialist market and limit order traders in a pure order driven market supply liquidity and immediacy to the market. However, while the ultimate goal of the market maker is to provide an orderly and smooth market by continuously posting bid and ask quotes, limit order traders have much more freedom in their quotes. Intraday pattern of spreads and depths in a specialist market is the result of successive decisions by a single market maker while that in a pure order driven market is determined by many limit order traders. Nevertheless, due to the competition among limit order traders, we would expect that the pattern is the same in both market architectures.

\subsection{Intraday Variation in Bid-Ask Spreads, Volumes, and Depths}

In this section, we examine the intraday variation in spreads, depths, and volumes in a pure order-driven market. We partition each trading day into 13 successive 30 -minute intervals and then calculate the average standardized spread, depth, and volume for each stock during each of the 30-minute intervals. The standardized value is obtained by subtracting the mean for the day from the value and dividing the difference by the standard deviation for the day for the respective stock. Table 1 reports the cross sectional mean values for standardized volumes, spreads, and depths for each 30-minute interval of the day.

The bid-ask spreads are highest at the beginning of the day, narrows until late morning and then increase very slightly during late afternoon. This result confirms the U-shaped pattern documented in many studies such as Chan et al (1995), Chung et al (1999) in a specialist market. Thus, along with other findings, our result suggests that the U-shaped pattern of spreads does not depend on the market architectures. Whether it is an orderdriven market or a specialist market, bid-ask spreads display a U-shaped pattern. Indeed, Chung et al (1999) show that even though the market maker sets bid and ask prices in the NYSE, the U-shaped intraday pattern of spreads largely reflects the intraday variation in spreads established by limit order traders. 


\section{Table 1}

This table reports the mean values for the standardized trading volumes, bid-ask spreads and depths of 31 component stocks in the TSE35 index for each time interval during the day. The standardized variable is defined as $(X-\mu) / \sigma$ where $X$ is the raw variable, $\mu$ is the mean of $X$ for the day, and $\sigma$ is the standard deviation of $X$ for the day.

\begin{tabular}{rrrr}
\hline Time & $\begin{array}{c}\text { Standardized } \\
\text { Volume }\end{array}$ & $\begin{array}{c}\text { Standardized } \\
\text { Spread }\end{array}$ & $\begin{array}{c}\text { Standardized } \\
\text { Depth }\end{array}$ \\
\hline 9:30-10:00 & -0.031311 & 0.523855 & -0.242232 \\
$10: 01-10: 30$ & 0.006585 & 0.111237 & -0.101693 \\
$10: 31-11: 00$ & -0.001707 & 0.005147 & -0.009235 \\
$11: 01-11: 30$ & -0.003119 & -0.088074 & 0.049991 \\
$11: 31-12: 00$ & -0.004632 & -0.10714 & 0.038552 \\
$12: 01-12: 30$ & -0.007843 & -0.119627 & 0.034728 \\
$12: 31-13: 00$ & -0.018975 & -0.134378 & 0.005268 \\
$13: 01-13: 30$ & -0.024468 & -0.127337 & 0.037791 \\
$13: 31-14: 00$ & -0.008385 & -0.098485 & 0.056594 \\
$14: 01-14: 30$ & -0.008157 & -0.129938 & 0.053264 \\
$14: 31-15: 00$ & -0.00025 & -0.145834 & 0.076920 \\
$15: 01-05: 30$ & -0.001182 & -0.133749 & 0.063579 \\
$15: 31-16: 00$ & 0.0337 & -0.084251 & 0.111489 \\
\hline
\end{tabular}

Trading volume intraday pattern differs from that of spreads. Volume is at the lowest when the market opens, increases significantly after half an hour, and then gradually decline until early afternoon. It increases for the rest of the day. However, the significant rise is in the last half hour of the trading day. Despite that, volume is rather stable relative to spread. Our result is different from that of Chan, Chung, and Johnson (1995) in the NYSE. Chan et al find that the intraday pattern of volume mimics that of spreads, i.e. Ushaped pattern. There are a couple of reasons for the lowest volume at the opening. First, uncertainty is high at the beginning of the day due to the overnight non-trading period. 
Second, trading costs are the highest at the beginning (since spread is widest when the market opens). Trading volume rises from early in the afternoon until the market closes.

Depths exhibit a completely different intraday pattern. The market is very thin at the open, and then it becomes deeper and deeper in the next one and a half hour. After that it is rather stable. This pattern is consistent with information models which predict that the market is illiquid at the open (wide spread and low depth) due to high information asymmetry which results from the overnight non-trading period.

To formally examine the intraday behavior of bid-ask spreads, depths and volumes we use the following models.

$$
S T V_{i}=a_{0}+a_{1} D_{1}+a_{2} D_{2}+a_{3} D_{3}+a_{4} D_{4}+a_{5} D_{5}+a_{6} D_{6}+\varepsilon_{i},
$$

where $S T V_{i}$ is the $i^{\text {th }}$ observation of the standardized variable (bid-ask spread, depth or volume) of the stock and $D_{1}-D_{6}$ are dummy variables.

$D_{1}=1$ if the interval is 9:30-10:00, and 0 otherwise;

$D_{2}=1$ if the interval is 10:01-10:30, and 0 otherwise;

$D_{3}=1$ if the interval is 10:31-11:00, and 0 otherwise;

$D_{4}=1$ if the interval is 14:31-15:00, and 0 otherwise;

$D_{5}=1$ if the interval is 15:01-15:30, and 0 otherwise;

$D_{6}=1$ if the interval is $15: 31-16: 00$, and 0 otherwise.

$\alpha_{0}$ measures the average of the standardized variable from 11:01 to $14: 30$ and $\alpha_{1}-\alpha_{6}$ measure the difference between the mean of the standardized variable in the respective interval and the average of the standardized variable from 11:01 to 14:30.

$\alpha_{0}$ measures the average of the standardized variable from 11:01 to $14: 30$ and $\alpha_{1}-\alpha_{6}$ measure the difference between the mean of the standardized variable in the respective interval and the average of the standardized variable from 11:01 to 14:30. 


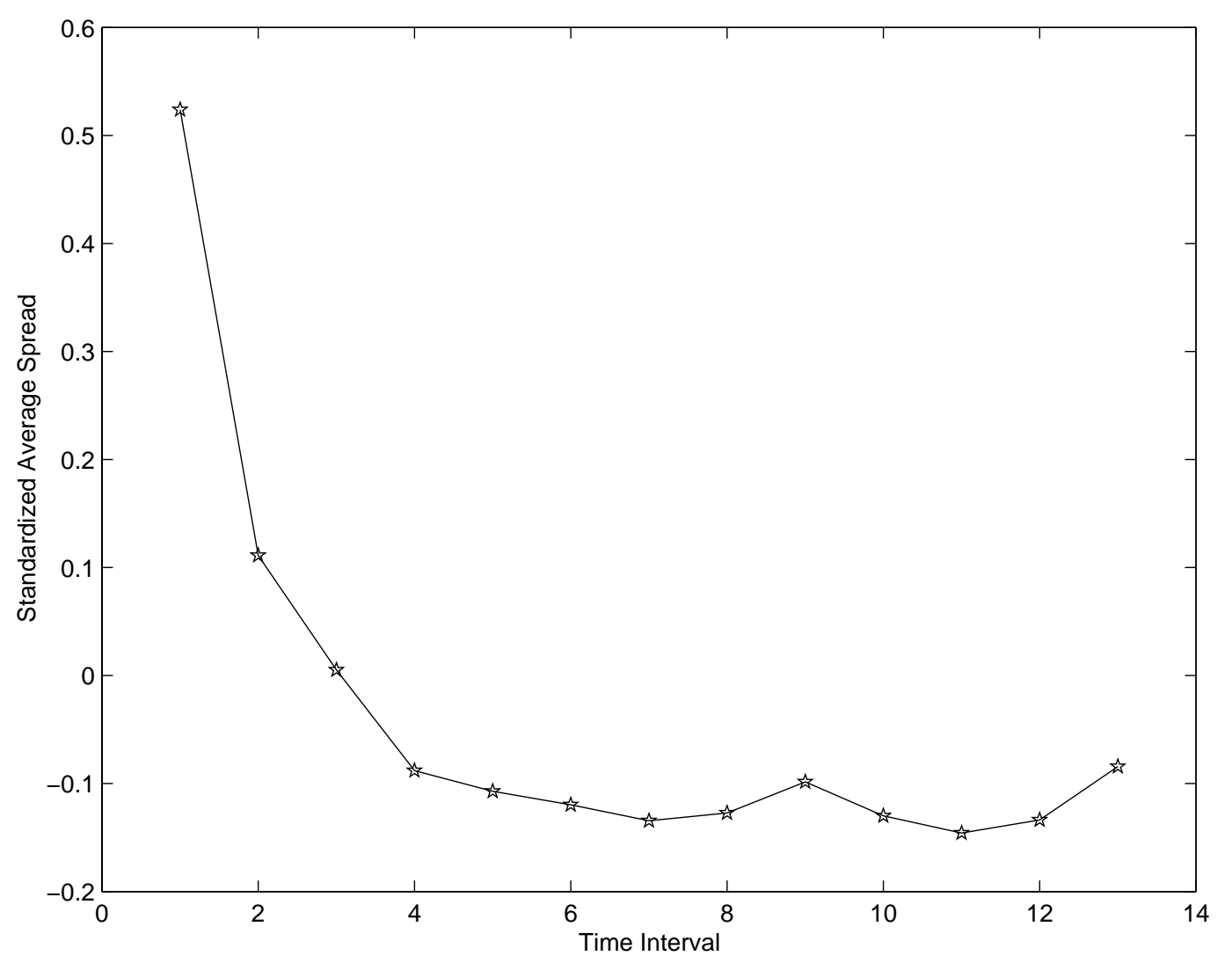

Figure 1: The Intraday Variation in the Standardized Spread.

We define the standardized spread as $(S-\mu) / \sigma$ where $S$ is the quoted spread, $\mu$ is the mean of quoted spread for the day, and $\sigma$ is the standard deviation of the quoted spread for the day.

We estimate this model for each of 31 stocks using the Generalized Method of Moments (GMM) with Newey and West (1987) correction for serial correlation and heteroskedasticity. We obtain t-statistics which are robust to heteroskedasticity and autocorrelation. The results are reported in Table 2. For each dummy variable, we report the average coefficient from the regression of each individual stock and also the percentage of stocks with positive coefficient.

To test whether each coefficient is significantly greater than zero we use the procedure outlined in Meulbroek (1992). Specifically, assume that the individual stock regression tstatistics asymptotically follow a unit normal distribution, then the Z-statistic to test 
whether the mean regression coefficient for each dummy variable is greater than zero is given by

\section{Table 2}

This table presents the GMM estimates of the following model for each of the 31 component stocks in the TSE-35 index.

$$
S T V_{i}=\alpha_{0}+\alpha_{1} D_{1}+\alpha_{2} D_{2}+\alpha_{3} D_{3}+\alpha_{4} D_{4}+\alpha_{5} D_{5}+\alpha_{6} D_{6}+\varepsilon_{i}
$$

where $S T V_{i}$ is the $i^{\text {th }}$ observation of the standardized variable (bid-ask spreads, depths or volumes) and $D_{1}-D_{6}$ are dummy variables. $D_{1}=1$ if the interval is 9:30-10:00, and 0 otherwise; $D_{2}=1$ if the interval is 10:01-10:30, and 0 otherwise; $D_{3}=1$ if the interval is 10:31-11:00, and 0 otherwise; $D_{4}=1$ if the interval is 14:31-15:00, and 0 otherwise; $D_{5}=1$ if the interval is 15:01-15:30, and 0 otherwise; $D_{6}=1$ if the interval is 15:31-16:00, and 0 otherwise. Thus, $\alpha_{0}$ measures the average of the standardized variables from 11:01 to 14:30 and $\alpha_{1}-\alpha_{6}$ measure the difference between the mean spread in the respective interval and the average spread from 11:01 to 14:30.

\begin{tabular}{rlrrr}
\hline & & SSpread & SVolume & SDepth \\
\hline$D_{1}$ & Average & 0.621264 & -0.03172 & -0.282695 \\
& Positive coefficient (\%) & 96.77 & 22.58 & 9.68 \\
& Z statistic & 53.03 & -7.6 & -28.96 \\
& p-value from Z statistic & 0.0000 & 0.0000 & 0.0000 \\
$D_{2}$ & Average & 0.217418 & 0.006175 & -0.142156 \\
& Positive coefficient (\%) & 96.77 & 45.16 & 12.9 \\
& Z statistic & 20.96 & 1.548198 & -13.7093 \\
& p-value from Z statistic & 0.0000 & 0.060787 & 0.0000 \\
$D_{3}$ & Average & 0.1135 & -0.002116 & -0.049697 \\
& Positive coefficient (\%) & 87.1 & 48.39 & 32.26 \\
& Z statistic & 9.47 & -0.301737 & -4.41 \\
& p-value from Z statistic & 0.0000 & 0.38142 & 0.0000 \\
$D_{4}$ & Average & -0.038037 & -0.000659 & 0.036457 \\
& Positive coefficient (\%) & 32.26 & 58.06 & 64.52 \\
& Z statistic & -4.01 & -0.181401 & 3.05 \\
& p-value from Z statistic & 0.9871 & 0.2357 & 0.01 \\
$D_{5}$ & Average & -0.025375 & -0.001591 & 0.023116 \\
& Positive coefficient (\%) & 38.71 & 51.62 & 61.29 \\
& Z statistic & -2.23 & -0.720217 & 2.35 \\
& p-value from Z statistic & 0.9871 & 0.2357 & 0.01 \\
$D_{6}$ & Average & 0.036085 & 0.033291 & 0.071026 \\
& Positive coefficient (\%) & 64.52 & 83.87 & 67.74 \\
Z statistic & 3.84 & 6.14 & 7.06 \\
p-value from Z statistic & 0.0000 & 0.0000 & 0.0000 \\
\hline
\end{tabular}




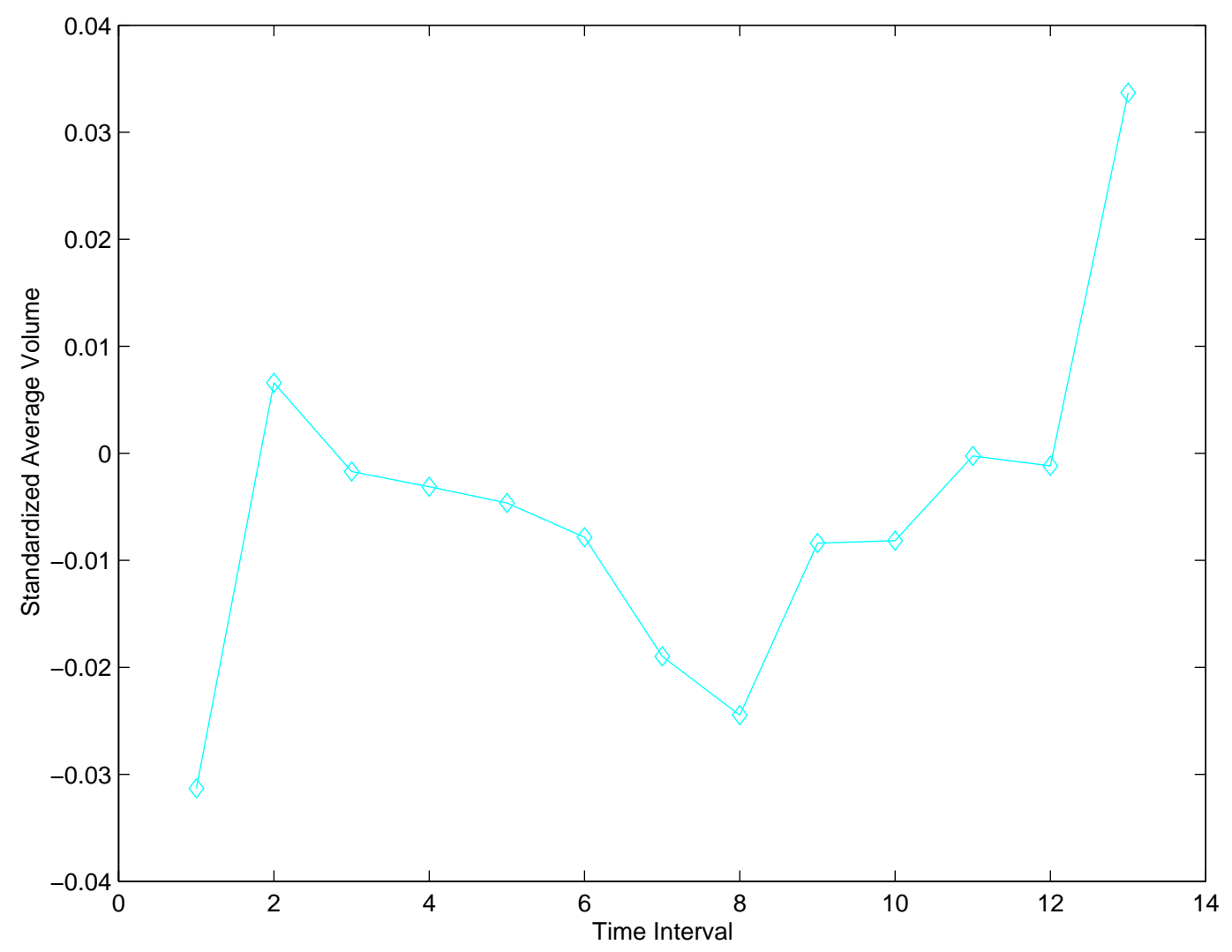

Figure 2: The Intraday Variation in the Standardized Volumes

We define the standardized volume as $(V-\mu) / \sigma$, where $V$ is the volume of trade, $\mu$ is the mean of volume for the day, and $\sigma$ is the standard deviation of the volume for the day.

$$
Z=\frac{1}{\sqrt{N}} \sum_{i=1}^{N} t_{i},
$$

where $\mathrm{N}$ is the number of stocks. This test assumes that individual stocks are independent. If this assumption does not hold, our econometric specification is not perfect.

The results in Table 2 show that the bid-ask spreads are widest at the open, narrow during the day, and rise during the last 30-minute interval. During the two intervals before the last, the spreads are not significantly greater than the average spread during midday. 
Overall, our empirical results are inconsistent with the prediction of Madhavan (1992) in which private information is impounded into prices as trading continues; therefore, bidask spreads decline throughout the day. Our results appear consistent with the specialist market power models and the inventory models. However, since TSE is a pure orderdriving exchange in which there are no market makers, the monopolistic behavior of specialists is not the explanation for the observed intraday patterns of the bid-ask spreads. An alternative explanation is that because of increased uncertainty at the open and the imminent non-trading period at the close, liquidity providers tend to increase (decrease) prices when submitting limit sell (buy) orders.

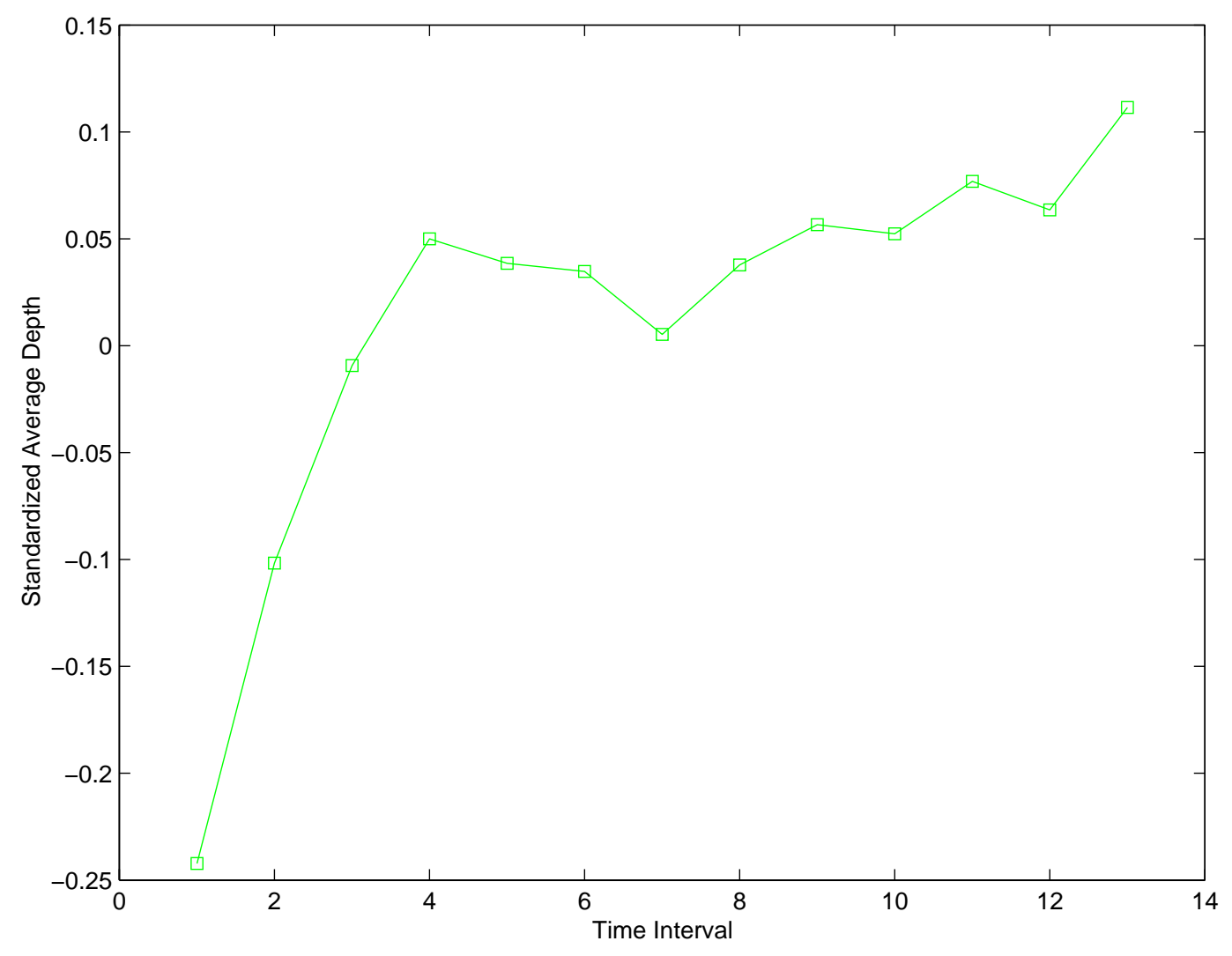

Figure 3: The Intraday Variation in the Standardized Depths

We define the standardized depth as $(D-\mu) / \sigma$, where $D$ is the quoted depth, $\mu$ is the mean of quoted depth for the day, and $\sigma$ is the standard deviation of quoted depth for the day. 
For transaction volumes, only $\alpha_{1}$ is significantly less than zero, and $\alpha_{6}$ is significantly greater than zero. $\alpha_{2}-\alpha_{5}$ are not significantly different from zero. Thus, volumes are low during the first half hour at the open, then become stable during the day and rise in the last half hour of the trading day.

For market depths at quoted prices, $\alpha_{1}-\alpha_{3}$ are significantly less than zero, suggesting that the market is thin at the open. Moreover, $\alpha_{1}<\alpha_{2}<\alpha_{3}$ tells us that the market becomes deeper as trading continues. However, the behavior at the end of the trading day is not clear. Even though $\alpha_{6}>\alpha_{5}$ but $\alpha_{5}<\alpha_{4}$. In addition, the percentage of stocks with positive coefficients is only 64.52 for $\alpha_{4}, 61.29$ for $\alpha_{5}$, and 67.74 for $\alpha_{6}$. Thus, there is no clear evidence that the market depth at the end of the day differs from that at the middle of the day.

\section{THE RELATION AMONG LIQUIDITY, VOLUME, AND PRICE VOLATILITY}

\subsection{The Theoretical Relation between Liquidity, Volume, and Price Volatility}

Harris (1990) defines liquidity as follows. “A market is liquid if traders can buy or sell large number of shares when they want and at low transaction costs. Liquidity is the willingness of some traders (often but not necessarily dealers) to take the opposite side of a trade that is initiated by someone else, at low cost.” This definition implies that spread and depth are two dimensions of market liquidity.

Lee Mucklow and Ready (1993), Ye (1995) argue that if the specialist believes that there is an increase in the probability of informed trades he would respond by increasing the bid-ask spread. Alternatively, he could reduce the depth at the quoted prices. Kavajecz (1999) shows that depth is used as a strategic variable by specialists to deal with risks associated with information events. Specifically, Kavajecz finds that liquidity providers, 
both market maker and limit order traders, reduce depths around earning announcements to decrease adverse selection costs. Logically, we can extend the reasoning to the case of order-driven market. On the TSE, a complete quote includes the bid and ask prices and the market depths which are the number of shares available at each quoted price. All liquidity in this exchange is provided by limit orders. If limit order traders believe that informed traders have arrived, they may respond by posting lower (higher) bid (ask) prices, and/or reducing the depth at each quoted price. This consideration leads us to the first hypothesis.

Hypothesis 1: There is an inverse relationship between bid-ask spread and market depth.

Handa and Schwartz (1996) argue that when transaction prices move solely in response to information, trading via limit order is suboptimal because investors who place a buy (sell) limit order have written a free put (call) option to the market. They show that if the price is very volatile, traders submit more limit orders than market orders because the expected gains exceed the expected losses from trading against informed traders. Foucault (1999) develops a model in which he endogenizes investors' decision to trade via limit orders or market orders. He finds that price volatility is a main determinant of limit orders. If the price volatility rises, the probability of trading against an informed trader increases; therefore, the expected losses to them are larger. To deal with the problem, limit order traders have to widen spreads by increasing (decreasing) ask (bid) prices and/or to reduce the quantity offered (demanded) at each quoted price. Moreover, in this case, choosing market order is even a worse strategy because it is more likely that the order is executed at a poor price when the price volatility increases. Those considerations lead us to the second hypothesis.

Hypothesis 2: There is an inverse relationship between price volatility and market liquidity. 
In Easley and O'Hara (1992) volume is a main determinant of spread. In particular, the spread exists because of the possibility of trading against informed traders. High trading volume is considered as an indication of the advent of informed traders. Initially, the market maker sets the spread based on the ex ante probability of informed trades and then increases (decreases) it if there is an abnormally high (low) volume of trade. Thus, this model predicts that high volume is accompanied by wide spread. The model does not consider market depth since a unit trade size is assumed. However, a logical extension of the model is that depth would decrease with volume. In addition, because the volume is positively related to the number of transactions, we will therefore have to control for the impact of the number of transaction in our empirical analysis. Although the model is developed in the context of a specialist market, we conjecture that the results also apply to a pure order-driven market. Those considerations lead us to the third hypothesis.

Hypothesis 3: There is an inverse relationship between volume and market liquidity.

\subsection{Empirical Methodology}

\subsubsection{Time Interval}

Each trading day commences at 9:30 and ends at 16:00 and will be partitioned into 13 half hour intervals. Since intraday observations are separated by overnight and weekend periods, the time series are not uniform in terms of interval length.

\subsubsection{Price Volatility}

The price volatility in interval $t$ is computed as

$$
\text { VOLATI }=\sum_{j=1}^{N} R_{j, t}^{2} \text {, where } R_{j, t}=\frac{P_{j, t}}{P_{j-1, t}}-1 \text {. }
$$


Thus, $R_{j, t}$ is the return of the $j^{\text {th }}$ transaction in the time interval $t$ and $N$ is the total number of transactions in interval $t$. Traditionally, the price volatility is calculated by $\frac{1}{N} \sum_{j=1}^{N}\left(R_{j, t}-\bar{R}\right)^{2}$. In this paper, we assume that the mean return $\bar{R}$ in each interval is equal to zero and thus, we do not subtract it from $R_{j, t}$. This is a reasonable assumption given the fact that the interval is short (half hour). In addition, in computing the price volatility, we do not divide the sum of squared returns by the number of transaction since we would like to measure the cumulative price fluctuation rather than the average price fluctuation for each transaction.

\subsubsection{Spread, Market Depth, and Volume}

Spread is defined as the difference between the ask price and the bid price. Market depth is measured by the total number of shares posted at the quoted prices.

$$
\mathrm{DEPTH}_{t}=\mathrm{DEPTH}_{t}^{\text {bid }}+\mathrm{DEPTH}_{t}^{\text {ask }},
$$

where $D E P T H_{t}^{\text {bid }}$ and $D E P T H_{t}^{\text {ask }}$ are the number of shares posted at the bid price and ask price respectively. Volume variable is measured by the total number of shares traded in interval t.

\section{EMPIRICAL RESULTS}

\subsection{The Relation between Spreads and Depths}

To examine the relation between spreads and depths, we estimate the following regression for each stock.

$$
\mathrm{SDEPTH}_{t}=a_{0}+a_{1} \operatorname{SSPRD}_{t}+a_{2} \mathrm{SDEPTH}_{t-1}+\sum_{i=1}^{11} \theta_{i} \operatorname{TIME}_{i, t}+u_{t},
$$


$S S P R D_{t}$ is the standardized spread in interval $t, S D E P T H_{t}$ is the standardized depth at the end of interval $t$, and $T I M E_{i, t}$ is a dummy variable that takes the value of 1 if $i=t$ and 0 otherwise, $u_{t}$ is the error term. We include $T I M E_{i, t}$ and $S D E P T H_{t-1}$ on the right hand side of the equation in order to control for the intra-day variation and autocorrelation in the dependent variable. Even though there are 13 time intervals every day, there are only 12 observations since $S D E P T H_{t-1}$ is used as an explanatory variable. Moreover, to avoid multicollinearity we do not assign a dummy variable to one interval. Thus, we only have 11 dummy variables.

We estimate this model for each stock using the GMM with the Newey and West (1987) correction. We obtain t statistics that are robust to heteroskedasticity and autocorrelation. As in the last section, to test whether each coefficient significantly differs from zero we use the procedure outlined in Meulbroek (1992). The regression results are reported in Table 3.

\section{Table 3}

This table reports the GMM estimates of the following regression model for each of 31 component stocks in the TSE-35 index.

$$
\mathrm{SDEPTH}_{t}=a_{0}+a_{1} \mathrm{SSPRD}_{t}+a_{2} \mathrm{SDEPTH}_{t-1}+\sum_{i=1}^{11} \theta_{i} \mathrm{TIME}_{i, t}+u_{t},
$$

where $S P R D_{t}$ is the standardized spread in interval $t, S D E P T H_{t}$ is the standardized depth at the end of interval $t$, and $T I M E_{i, t}$ is a dummy variable that takes the value of 1 if $i=t$ and 0 otherwise, $u_{t}$ is the error term.

\begin{tabular}{lrr}
\hline & $a_{1}$ & $a_{2}$ \\
\hline Average coefficient & -2.9232 & 0.2592 \\
Negative coefficients (\%) & 74.19 & 0 \\
Z-statistic & -2.54 & 22.4938 \\
p-value & 0.0017 & 0.0000 \\
\hline
\end{tabular}


We find that the depth is significantly and negatively related to the spread. This result is consistent with hypothesis 1 and supports the view that limit order traders use both bidask spread and depth as means to respond to any indication that the probability of informed trades has risen.

\subsection{The Impacts of Price Volatility, Trading Activity, and Transaction Volume on Market Liquidity}

To investigate the impacts of price volatility, transaction volume, and trading activity on market liquidity, we estimate the following linear models for each stock.

$$
\begin{aligned}
& \operatorname{SSPRD}_{t}=\alpha_{1}+\beta_{1} \text { VOLATI }_{t-1}+\gamma_{1} N T_{t}+\delta_{1} \text { SVOLUME }_{t}+\sum_{i=1}^{11} \theta_{i} \operatorname{TIME}_{i, t}+\varphi_{1} \operatorname{SSPRD}_{t-1}+\varepsilon_{t}, \\
& \text { SDEPTH }_{t}=\alpha_{2}+\beta_{2} \text { VOLATI }_{t-1}+\gamma_{2} N T_{t}+\delta_{2} \text { SVOLUME }_{t}+\sum_{i=1}^{11} \theta_{i} \operatorname{TIME}_{i, t}+\varphi_{2} \text { SDEPTH }_{t-1}+u_{t},
\end{aligned}
$$

where $S S P R D_{t}$ is the standardized spread in time interval $t, S D E P T H_{t}$ is the standardized market depth at the end of time interval $t, V O L A T I_{t-1}$ is the volatility during time interval $t-1, N T_{t}$ is the number of transactions during time interval $t, S V O L U M E_{t}$ is the standardized volume during time interval $t$, and $T I M E_{i, t}$ is a dummy variable that takes the value of 1 if $i=t$ and 0 otherwise. The inclusion of $T I M E_{i, t}$ and $S P R D_{t-1}$ on the right hand side of the first equation and $T I M E_{i, t}$ and $S D E P T H_{t-1}$ on the right hand side of the second equation is to control for the intra-day variation and autocorrelation in the dependent variables.

The results are reported in Table 4. For brevity, the estimates of $\theta_{i}$ are not reported here. However, these coefficients are significantly different from zero, indicating that it is necessary to control for the intra-day effects.

Theoretically, there are 2 effects of the number of transactions on market liquidity. On one hand, transactions consume the liquidity available in the market and therefore there 
should be an inverse relationship between market liquidity and the number of trades. In other words, spread (depth) should be positively (negatively) related to the number of trades. On the other hand, higher trading activities may capture market interest and induce investors to supply more liquidity to the market as shown in Admati and Pfleiderer (1988) and thus, there is a negative (positive) relationship between spread (depth) and the number of trades. Our empirical results show that the first effect dominates the second one. Ahn, Bae and Chan (2001) also find that there is a negative relationship between depth and number of transaction in the Stock Exchange of Hong Kong.

We find that the price volatility is positively (negatively) related to spread (depth). This result is consistent with the predictions of Handa and Schwartz (1996), and Foucault (1999) and therefore supports our hypothesis 2. Indeed, if the price is very volatile, the probability that a limit order is executed is higher even though bid - ask spread is wide. As a result, investors tend to submit limit orders with lower bid prices and higher ask prices. This leads to higher bid-ask spread and lower depth at the best quote.

The relationship between volume and spread is more complex. We find that there is a negative relationship between spread and volume and there is a positive relationship between depth and volume. In other words, volume is directly related to market liquidity. This result is inconsistent with the predictions of Easley and O'Hara (1992) and therefore does not support our hypothesis 3 . However, this can be explained by the model of Harris and Raviv (1993). Harris and Raviv assume that traders share prior beliefs and receive common information but differ in the way they interpret the information. Thus, high volume could mean high liquidity trades and as a result spread should decrease and depth should increase. Those establish the direct relationship between volume and market liquidity. 


\section{Table 4}

This table presents the GMM estimates of the following regression models for each of 31 component stocks in the TSE-35 index.

$\operatorname{SSPRD}_{t}=\alpha_{1}+\beta_{1} \operatorname{VOLATI}_{t-1}+\gamma_{1} N T_{t}+\delta_{1} \operatorname{SVOLUME}_{t}+\sum_{i=1}^{11} \theta_{i} \operatorname{TIME}_{i, t}+\varphi_{1} \operatorname{SSPRD}_{t-1}+\varepsilon_{t}$,

$\mathrm{SDEPTH}_{t}=\alpha_{2}+\beta_{2}$ VOLATI $_{t-1}+\gamma_{2} N T_{t}+\delta_{2} \mathrm{SVOLUME}_{t}+\sum_{i=1}^{11} \theta_{i} \operatorname{TIME}_{i, t}+\varphi_{2} \mathrm{SDEPTH}_{t-1}+u_{t}$, whe

re $S S P R D_{t}$ is the standardized spread in time interval $t, S D E P T H_{t}$ is the standardized market depth at the end of time interval $t, V O L A T I_{t-1}$ is the volatility during time interval $t-1, N T_{t}$ is the number of transactions during time interval $t, S V O L U M E_{t}$ is the standardized volume during time interval $t$, and $T I M E_{i, t}$ is a dummy variable that takes the value of 1 if $i=t$ and 0 otherwise.

Panel A: Dependent variable is standardized spread

\begin{tabular}{lrrrr}
\hline & $\beta_{1}$ & $\gamma_{1}$ & $\delta_{1}$ & $\varphi_{1}$ \\
\hline Average coefficient & 0.192 & 0.0052 & -0.111 & 0.1742 \\
Positive coefficient (\%) & 64.52 & 77.42 & 32.26 & 100 \\
Z-statistic & 2.6923 & 4.5512 & -2.5683 & 18.2461 \\
p-value & 0.0035 & 0.0000 & 0.0051 & 0.0000 \\
\hline
\end{tabular}

Panel B: Dependent variable is standardized depth

\begin{tabular}{lrrrr}
\hline & $\beta_{2}$ & $\gamma_{2}$ & $\delta_{2}$ & $\varphi_{2}$ \\
\hline Average coefficient & -0.1893 & -0.00028 & 0.02921 & 0.252 \\
Positive coefficient (\%) & 67.74 & 64.52 & 19.35 & 0 \\
Z-statistic & -3.303 & -1.227 & 3.856 & 21.488 \\
p-value & 0.0005 & 0.11 & 0.000 & 0.0000 \\
\hline
\end{tabular}

\section{CONCLUDING REMARKS}

This paper examines the intraday behavior of the market liquidity in the Toronto Stock Exchange which uses a computerized limit order trading system. Along with previous studies, we confirm that the U-shaped intraday pattern of spread does not depend on the market architecture. Whether the exchange is order-driven, specialist, hybrid, or 
dealership, spread still displays a U-shaped intraday pattern. In addition, we show that the market is very thin at the opening but it becomes deeper and deeper as trades go on. After one and a half hours, it becomes stable. Our results also indicate that the volume of trade is low in the first half hour of the day and then stable until the last half hour when it rises.

Consistent with Harris (1990), our results show that limit order traders use both spread and depth to protect themselves from informed traders. If they believe that the probability that some traders possess superior information has increased, they would respond by widening spread and/or decreasing the depth at each quoted price. We find evidence that spread and depth are negatively correlated. Thus, as indicated by Harris (1990) and Lee, Mucklow and Ready (1993), spread and depth are two dimensions of market liquidity.

We find that price volatility is inversely related to market liquidity. When the price volatility increases, the probability of being bagged by informed traders also increases. Limit order traders have to post higher (lower) ask (bid) price and/or reduce the depth at each quote. This establishes the inverse relationship.

Finally, we show that there is a direct relationship between trading volume and liquidity. Harris and Raviv (1993) explain this result by postulating that traders receive the same information but they interpret the information in different ways. Thus, it could be the case that high volume implies high liquidity trade which leads to the increase in market liquidity. 


\section{APPENDIX}

Below are the names and the corresponding tick symbols of the 31 firms in the dataset

Symbol

A

AL

BMO

BNS

ABX

BCE

BVF

BBD.B

$\mathrm{CM}$

CNR

CP

CTR.A

CLS

DFS

MG.A

$\mathrm{N}$

NA

NCX

NT

PCA

PDG

RIM

RY

SJR.B

SU

TA

TD

TEK.B

TLM

TOC

TRP

\section{Company Name}

ABITIBI-CONSOLIDATED INC.

ALCAN INC.

BANK OF MONTREAL

BANK OF NOVA SCOTIA

BARRICK GOLD CORPORATION

BCE INC.

BIOVAIL CORPORATION

BOMBARDIER INC.

CANADIAN IMPERIAL BANK OF COMMERCE

CANADIAN NATIONAL RAILWAY CO.

CANADIAN PACIFIC

CANADIAN TIRE CORP.

CELESTICA INC.

DOFASCO INC.

MAGNA INTERNATIONAL INC.

INCO LIMITED

NATIONAL BANK OF CANADA

NOVA CHEMICALS CORPORATION

NORTEL NETWORKS

PETRO-CANADA

PLACER DOME INC.

RESEARCH IN MOTION LIMITED

ROYAL BANK OF CANADA

SHAW COMMUNICATIONS INC.

SUNCOR ENERGY INC.

TRANSALTA CORPORATION

TORONTO-DOMINION BANK

TECK COMINCO LIMITED

TALISMAN ENERGY INC.

THOMSON CORPORATION

TRANSCANADA PIPELINES LTD. 


\section{REFERENCES}

[1] Chan, K, Y. P. Chung, and H. Johnson, 1995, The Intraday behavior of Bid-Ask Spreads for NYSE Stocks and CBOE Options, Journal of Financial and Quantitative Analysis, Vol.30, 329-346.

[2] Brock, W., and A. Kleidon, 1992, Periodic Market Closure and Trading Volume: A Model of Intraday Bids and Asks, Journal of Economic Dynamic and Control, 16, 451-489.

[3] Chung, K. H., B. F. Van Ness, and R. A. Van Ness, 1999, Limit Orders and the Bid-Ask Spread, Journal of Financial Economics, 53, 255-287.

[4] Newey, W. K., and K. D. West, 1987, A Simple Positive Semi-definite Hesteroskedasticity and Autocorrelation Consistent Covariance Matrix, Econometrica, 55, 703-708.

[5] Gibbons, M., and Shanken, J., 1987, Subperiod Aggregation and the Power of Multivariate Tests of Portfolio Efficiency, Journal of Financial Economics 19, 389-394.

[6] Meulbroek, L., 1992, An Empirical Analysis of Illegal Insider Trading, Journal of Finance 47, 1661-1699.

[7] Madhavan, A., 1992, Trading Mechanism in Securities Markets, Journal of Finance 47, 607-642.

[8] Foster, F., and S. Viswanathan, 1994, Strategic Trading with Asymmetrically Informed Investors and Long-Lived Information, Journal of Financial and Quantitative Analysis 29, 499-518.

[9] Harris, L. E., 1990, Liquidity, Trading Rules, and Electronic Trading Systems, New York University Monograph Series in Finance and Economics, Monograph No. 1990-4.

[10] Handa, P. and R. A. Schwartz, 1996, Limit Order Trading, Journal of Finance 51, 1835-1861.

[11] Admati, A. R., and P. Pfleiderer, 1988, A Theory of Intraday Patterns: Volume and Price Variability, Review of Financial Studies 1, 3-40. 
[12] Harris, M. and A. Raviv, 1993, Differences of Opinion Make a Horse Race, Review of Financial Studies 6(3), p.473-506.

[13] Harris, L. and J. Hasbrouck, 1996, Market vs. Limit Orders: The SuperDot Evidence on Order Submission Strategy, Journal of Financial and Quantitative Anslysis 31, p.213 - 232.

[14] Ross, C. D., J. E. Shapiro, and K. A. Smith, 1996, Price Improvement of SuperDot Market Orders on the NYSE, Working Paper \#96-02, New York Stock Exchange.

[15] Glosten, L.R., 1994, Is the Electronic Open Limit Order Book Inevitable? Journal of Finance 49, p.1127-1161.

[16] Handa, P., and R. A. Schwartz, 1996, Limit Order Trading, Journal of Finance 51, p.1835-1861.

[17] Foucault, T., 1999, Order Flow Composition and Trading Costs in a Dynamic Limit Order Market, Journal of Financial Markets 2, p.193-226.

[18] Kavajecz, K., 1999, A Specialist's Quoted Depth and the Limit Order Book, Journal of Finance 54, p.747-771.

[19] Harris, L. E., 1990, Liquidity, Trading Rules, and Electronic Trading Systems, New York University Monograph Series in Finance and Economics, Monograph No.1990-4.

[20] Chung, K.H., B. F. Van Ness, and R. A. Van Ness, 1999, Limit Orders and the Bid-Ask Spread, Journal of Financial Economics 53, p.255-287.

[21] Lee, C. M., B. Mucklow, and M. J. Ready, 1993, Spreads, Depths, and the Impact of Earnings Information: An Intraday Analysis, Review of Financial Studies 6(2), p.345-374.

[22] Easley, D. and M. O'Hara, 1992, Time and the Process of Security Price Adjustment, Journal of Finance 47, p.577-605.

[23] Madhavan, A., 1992, Trading Mechanisms in Securities Markets, Journal of Finance 47, p.607-641.

[24] Harris, L., 1987, Transaction Data Tests of the Mixture of Distributions Hypothesis, Journal of Financial and Quantitative Analysis 22. p.127-141. 
[25] Ye, J., 1995, Bid-Ask Prices and Sizes: The Specialist's Optimal Quotation Strategy, Working Paper, University of Southern California.

[26] Kavajecz, K., 1999, A Specialist's Quoted Depth and the Limit Order Book, Journal of Finance 54, p.747-771. 


\section{University of Minnesota MoRRIS}

\section{Working Paper Series}

\section{Volume 1}

Ritual and Ceremony In a Contemporary Anishinabe Tribe, Julie Pelletier

The War for Oil or the American Dilemma of Hegemonic Nostalgia?, Cyrus Bina

The Virgin and the Grasshoppers: Persistence and Piety in German-Catholic America, Stephen Gross Limit Orders and the Intraday Behavior of Market Liquidity: Evidence From the Toronto Stock Exchange, Minh Vo 